\title{
Commentary: Surgical results for prosthetic valve endocarditis: Early pain but long-term gain
}

\author{
Carlo Olevano, MD, and Clifford W. Barlow, DPhil, FRCS (CTh)
}

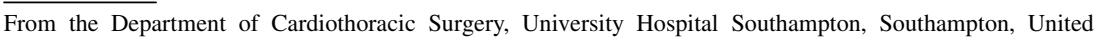
Kingdom.

Disclosure: Authors have nothing to disclose with regard to commercial support.

Received for publication Oct 3, 2019; accepted for publication Oct 3, 2019; available ahead of print Oct 24, 2019. Address for reprints: Clifford W. Barlow, DPhil, FRCS (CTh), Department of Cardiothoracic Surgery, University Hospital Southampton, Tremona Rd, Southampton, SO16 6YD, United Kingdom (E-mail: cliffbarlow@ hotmail.com).

J Thorac Cardiovasc Surg 2021;161:620-1

$0022-5223 / \$ 36.00$

Crown Copyright $@ 2019$ Published by Elsevier Inc. on behalf of The American Association for Thoracic Surgery https://doi.org/10.1016/j.jtcvs.2019.10.040
}

Prosthetic valve endocarditis (PVE) remains a dreaded complication of valve replacement, with redo-surgery for PVE historically associated with high mortality. ${ }^{1,2}$ As with all surgical challenges, current practice and outcomes need defining to find solutions to the difficulties posed in managing PVE. In this issue of the Journal, Weber and colleagues ${ }^{3}$ present the impact of native valve endocarditis (NVE) versus PVE on early postoperative and long-term survival. Although the early outcomes for PVE seem sobering, survival patterns after 1 year suggest important longterm benefits of surgery for PVE if short-term challenges are addressed.

The study, from 5 centers that comprise the German CAMPAIGN group, analyzed 4300 patients (3143 NVE, 1157 PVE) who underwent surgery between 1994 and 2016. Early postoperative outcomes confirmed much that is already known. First, that PVE had a 30-day postoperative mortality approximately twice that of NVE $(19.6 \%$ vs $10.6 \%$ ). Second, it confirmed reports ${ }^{4}$ that mitral valve endocarditis had worse outcomes than aortic valve endocarditis for both NVE and PVE. Third, multivariate analysis (MVA) confirmed factors known to be associated with a greater 30-day postoperative mortality, including age $>65$ years, diabetes, chronic pulmonary disease, and infection with staphylococcus spp.

However, there were interesting new findings in this study. ${ }^{3}$ Although MVA identified many of the same factors as risks for 1-year mortality and others, including female sex and coronary disease, it also found PVE itself to be independently predictive for both 30-day and 1-year mortality. Second, the mortality in both groups effectively doubled at 1 year to $21.6 \%$ in NVE and $36.4 \%$ in PVE. Third and most importantly, after adjusting for preoperative comorbidities, long-term survival after 1 year was comparable for both groups, with PVE not independently predictive for long-term mortality. The subanalysis of mitral and aortic

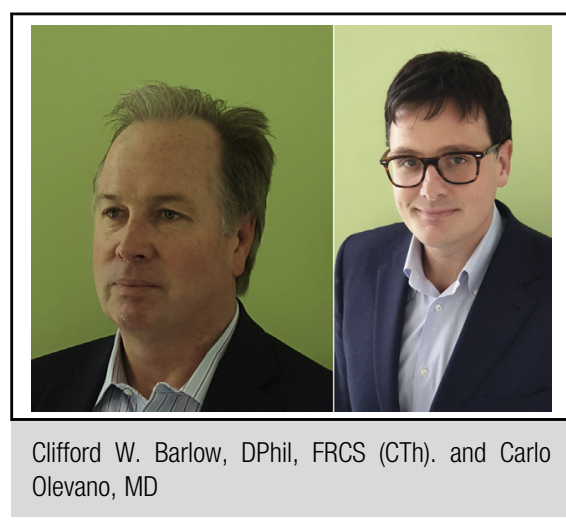

Central Message

Prosthetic valve endocarditis has an early postoperative mortality approximately twice that of native valve endocarditis, but long-term survival after 1 year is comparable for both groups

See Article page 609 endocarditis showed similar patterns as for NVE and PVE as a whole, both at 1 year and in the long term.

By virtue of the large patient numbers and comprehensive follow-up, the confirmatory and new information provided by the study $^{3}$ seem reliable and important, with outcomes in keeping with best international practice. Limitations of the retrospective analysis included heterogeneity of data collection and surgical management in different centers, and some variables that could not be analyzed were excluded, such as effect of mechanical versus tissue prosthesis. The authors' main recommendation is that the long-term survival justifies surgery in PVE.

A problem has to be defined to be solved. The current study $^{3}$ describes considerable challenges for PVE, with a 1 -year postoperative year mortality approaching $40 \%$ and not dissimilar to that reported decades ago. ${ }^{1,2}$ Surgical management is improving, so this static mortality in PVE may be because patients are now older with more comorbidities. Yet changing patient demographics apply to other conditions in cardiac surgery where mortality rates are reducing. ${ }^{5}$ Nevertheless, as survival may be equivalent for PVE as for NVE after the first year, we should focus on improving early postoperative results so patients with PVE can enjoy these long-term benefits. If PVE is advanced, with annular destruction or multivalve involvement and especially in older patients with comorbidities, then postoperative mortality will remain high. To diagnose PVE earlier therefore, 
greater vigilance is required in both suspecting PVE and also not relying on clinical or echocardiographic criteria that may apply more to NVE. Once PVE is diagnosed, early surgery is warranted in a specialist center. The study by Weber and colleagues suggests that, for patients with PVE, there will be "long-term gain after the early pain."

\section{References}

1. David TE, Gavra G, Feindel CM, Regesta T, Armstrong S, Maganti MD. Surgical treatment of infective endocarditis: a continued challenge. J Thorac Cardiovasc Surg. 2007;133:144-9.
2. Wolff M, Witchitz S, Chastang C, Régnier B, Vachon F. Prosthetic valve endocarditis in the ICU: prognostic factors of overall survival in a series of 122 cases and consequences for treatment decision. Chest. 1995;108:688-94.

3. Weber C, Petrov G, Luehr M, Aubin H, Tugtekin SM, Borger MA, et al. Surgical results for prosthetic versus native valve endocarditis: a multicenter analysis. J Thorac Cardiovasc Surg. 2021;161:609-19.e10.

4. Hussain ST, Shrestha NK, Gordon SM, Houghtaling MS, Blakstone EH, Pattersson GB. Residual patient, anatomic and surgical obstacles in treating active left-sided infective endocarditis. J Thorac Cardiovasc Surg. 2014;148:981-8.e4.

5. Nielson S, Björck L, Jeppsson A, Giang KW, Falk K, Määttä S, et al. Trends in mortality risks among 94,328 patients surviving 30 days after a first isolated coronary artery bypass graft procedure from 1987 to 2006: a population-based study. Int J Cardiol. 2017;244:316-21. 